\title{
KNOWLEDGE AND ATTITUDE OF MEDICAL STUDENTS TOWARDS RESEARCH AT RAWAL INSTITUTE OF HEALTH SCIENCES
}

\author{
Asma A Qadeer ${ }^{1}$, Mirza Inamul Haque ${ }^{2}$, Uzma Hassan $^{3}$, Sheikh Kashif Rahim ${ }^{4}$, Shakila Bangash $^{5}$ \\ ${ }^{1}$ Assistant Professor, Community Medicine Department, Rawal Institute Health Sciences, Rawalpindi. \\ ${ }^{2}$ Professor Community Medicine Department, Rawal Institute Health Sciences, Rawalpindi \\ ${ }^{3}$ Associate Professor Community Medicine Department, Rawal Institute Health Sciences, Rawalpindi \\ ${ }^{4}$ Assistant Professor, Community Medicine Department Rawal Institute Health Sciences, Rawalpindi \\ ${ }^{5}$ Demonstrator, Community Medicine Department, Rawal Institute Health Sciences, Rawalpindi \\ Correspondence: AsmaA Qadeer, email: asma_satti@yahoo.com
}

\begin{abstract}
Background: Research plays a prominent role in day to day life. Very little amount of literature is available on students interest and involvement in research in Pakistan, Most of the studies are quite old and new studies are required to identify the changing trends. It is therefore important to understand and highlight the attitudes and barriers of undergraduate medical students come across in conducting quality research.

Objective: Our study intended to assess the knowledge and attitude of medical students at RIHS towards research. Methods: A cross sectional study of five months duration was carried out at RIHS. Sample size of 224 MBBS students was taken, with $5 \%$ margin of error and $95 \%$ confidence level. Response rate was $67 \%$. Data was collected through close ended questionnaire and was analyzed using SPSS version 17/MS excel.

Results: Most (65\%) of the students only knew about research and its uses. The rest of $35 \%$ had no idea what research is about and what is the process. Out of those $65 \%$ who had knowledge, $39 \%$ students have conducted research in their life time, out of those $39 \%, 16 \%$ have previous exposure of conducting research at school, and $23 \%$ have done it as a part of mandatory training at medical college (RIHS). The rest of students have done it with their teachers as a part of the team.

Conclusion: The most important finding in this research was suggestion of enforcement of research project in the curriculum and as a part of their assessment and the preponderance of participating students considered it difficult to conduct research, with the most common barrier being lack of time, research training, schooling background, and the lack of motivation.
\end{abstract}

Keywords: Knowledge, attitude, medical students, research

\section{Introduction}

Research plays a prominent role in day to day life and it is one of the most important intellectual possessions for every human being to change his way of life in accordance to needs and demands of society. Research is a key ingredient in shaping up the world that man lives in and the new experiences they see and encounter in their surroundings (1).

Research in health is necessary in enlightening health care modalities and has a pivotal role in the field of medicine. The advancement in various disciplines of medicine such as disease surveillance, diagnosis, treatment and prevention all depend comprehensively on eminent research. In addition a quality research not only helps crafting a health care policy but also influences in refining health care policy (2). Conducting research also helps in enhancement of any ones critical thinking skills. The developing countries for many years have been counting on research outcomes by the developed countries. This however, does not always provide the explanation to the issues developing countries are facing. Slow advances however, have been made in medical research in developing countries and minimal funding, material and logistic support has been provided for conducting research $(3,4)$.

Very little amount of literature is available on students interest and involvement in research in Pakistan. Pakistan being a developing country has multiple healthcare, social, environmental psychological issues which need to be investigated. However, research here like most developing countries is in its infancy $(6,7)$. So, like other developing countries, Pakistan is also facing barriers in healthcare research. Except few quality researches, very little quality work is being produced, rest is compromised due to faulty methodology and no research training and background in field of research (5). 
Some studies however have looked at attitudes and interest in research among medical professionals and students worldwide. In the preventive medicine /public health sector, studies have found, time, financial constraints (8), lack of interest (9) and lack of knowledge as major deterrents to students involvement in research. Some other comparable studies recognized that encouragement through funding and logistics support is helpful in promoting research (10) Insufficient guidance and time constraints have been identified as barriers in conducting research $(11,12,13)$. Bland and Ruffin (14) and Brocato and Mavis (15) identified accessible resources, appropriate rewards, time allocation, promotion and tenure as stimulators for research and scholarly productivity.

Some efforts are being made to improve training in research both at undergraduate and post graduate level yet research output still remains low (16). Most of the research being produced is through required papers, generated by postgraduate trainees, (17) which is a mandatory requirement for their training, and for undergraduate students for whom it's compulsory as a subject. Other studies are quite old therefore new studies are required to identify any changing trends. So considering this as important to understand and highlight the attitudes and problems of medical students in conducting quality research. Our study may help identify barriers and find ways to encourage further research by medical students so that future research is more in number, better in quality and greater in impact.

\section{Methodology}

A cross sectional, observational study was carried out at Rawal Institute of Health Sciences, Islamabad. The duration of study was five months, from June 2016 to September 2016.Sampling frame was of 532 students of MBBS. Sample size of 224 was calculated by sample size calculator with confidence level of $95 \%$ and $5 \%$ margin of error. Response rate was $67 \%$. So a total number of 150 eligible consenting study participants from MBBS course responded for the study. Data was collected through a pretested; structured, close ended questionnaire to find out the knowledge and attitude of medical students towards research. The questionnaires were distributed to the participants who consented for the study by the help of researchers, the participants were given the participant information sheet and consent form and was got signed. Researchers picked the participants in groups of seven to eight students from each year of medical course of Rawal Institute of Health Sciences, explained the whole purpose of the research and the process to fill the questionnaire, and any ambiguity that could have been created. The study was approved by the Ethical Committee of Rawal Institute of Health Sciences. Assurance was given to the study population that the confidentiality of the information will be maintained at all times.

The questionnaire consisted of three parts namely; student's profile, evaluation of student's knowledge and attitude towards health research. Demographic details of subjects included age, gender, place of origin, type of high school course and year of study. The high schools were classified into Pakistani Higher Secondary School Certificate (HSSC), British Advanced Levels (A-levels) and others. Knowledge was assessed by ten multiplechoice questions. For each student, the percentage of correct answers was calculated as a representative of knowledge score. Six questions were asked to assess the attitudes of students towards health research and each answer was scored on a scale of 0.0 (unfavorable attitude) to 1.0 (favorable attitude). For each individual, score of individual questions was summed and then converted into percentage to represent the attitude score.

Data was analyzed using Statistical Package for Social Sciences (SPSS) version 17/MS excel

\section{Results}

Table 1 shows that out of 150 students $65 \%$ only knew, what research is what are the uses of research, its implications and the rest of $35 \%$ had no idea what research is about.

Out of $65 \%$ who had knowledge about research $39 \%$ students had conducted research in their life time. Out of those $39 \%, 16 \%$ have previous exposure of conducting research at school, and $23 \%$ had done it as a part of mandatory training at Medical College (RIHS). The rest of students had done it with their teachers as a part of the team.

Table 1: Demographic characteristics of the study participants $\mathrm{N}=150$

\begin{tabular}{|l|l|}
\hline Demographic Characteristics & Percentage (\%) \\
\hline Males & 37 \\
\hline Females & 63 \\
\hline First year & 7 \\
\hline Second year & 24 \\
\hline Third Year & 34 \\
\hline Fourth year & 13 \\
\hline Final year & 22 \\
\hline HSSC & 77 \\
\hline British Advanced Levels & 23 \\
\hline
\end{tabular}

Students with Cambridge schooling background (23\%) were aware of conducting research and 16\% had conducted research projects at least once during their course of study, while majority $(77 \%)$ of the study subjects had not obtained research training during their school period.

Out of 150 students, $61 \%$ students who never conducted research, of them $50 \%$ were found to have opinion that, no motivation for research was the main factor due to which they never conducted any research. $25 \%$ thought that if it gets inculcated in curriculum then they would 
conduct research.11\%thought there should be proper training on how to conduct research, lack of training has restricted them to conduct research. $11 \%$ think they don't have time to conduct research.

Out $39 \%$ who conducted research in their life time, $26 \%$ have done it through self-motivation, $56 \%$ were motivated by teachers $9 \%$ by fellows and $9 \%$ by parents.

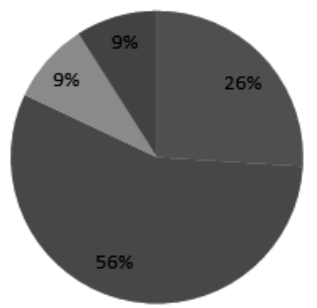

$$
\begin{aligned}
& \text { - Self } \\
& \text { - Teachers } \\
& \text { = Fellows } \\
& \text { - Parents }
\end{aligned}
$$

Figure 1: Percent of source of motivation

Attitude was measured with the help of factors like, Usefulness of research in a career, Relevance of the research to life, Research anxiety, Research difficulty and Positive attitudes towards research. Perceived barriers were also highlighted by the students such as a shortage of time and a lack of adequate mentoring.

Table 2: Attitude of Medical students towards research

\begin{tabular}{|l|l|l|}
\hline Variables & Yes & No \\
\hline Research Usefulness & $17 \%$ & $83 \%$ \\
\hline Interest in research & $70 \%$ & $30 \%$ \\
\hline Research Anxiety & $51 \%$ & $49 \%$ \\
\hline Research Difficulty & $76 \%$ & $24 \%$ \\
\hline
\end{tabular}

Relevance to Life) 1 ple of 150 st33\%?nts $83 \%$ stt67\% 6 nts think research is useful in their future and $17 \%$ think it's not helpful in any way. Out of those $83 \%, 10 \%$ believe it's good for their career $37 \%$ think it leads to an expansion of knowledge. $43 \%$ are of opinion that it leads to discoveries of new medical treatment and cures and only $7 \%$ believe that it can provide important information about disease and risk factor and the remaining $3 \%$ thinks policy and planning can be done with the help of research. Among $51 \%$ (76) students 38 were male and females were also 38 in number, who had anxiety about conducting research.
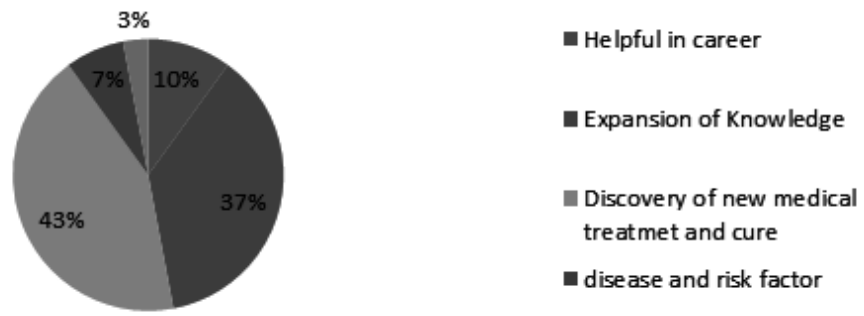

Figure 2: Percent of responses regarding usefulness of research in future
Lastly we also tried to identify what motivates students towards the research by getting their input, according to which $44 \%$ said that if it is made compulsory for medical students then they will get to know about research and will change the attitude towards research.16\% thought that organizing symposium to make them aware of importance of research would help. $40 \%$ thought that motivating them towards research in community medicine lectures would be helpful.

\section{Discussion}

Students at the undergraduate level usually tend to view research methods courses negatively $(18,19)$. Attitude towards research is the significant indicator for academic performance and achievement. The more positive attitudes towards an academic subject, the higher the possibility for an individual to perform well academically. (20) Attitude towards research among the medical professionals is variable and research experience during graduate period is strongly associated with postgraduate research initiatives and future career achievements in academic activities. (17) Attitude towards research is variable and proper education with intensive training after assessing the attitude helps the individuals to change the individual's attitude more favorable and helps in better ongoing of research. Our study also revealed that there was a positive relationship between student's research selfefficacy, and some of their previous research work. Earlier studies on research attitudes found that several factors such as personal and professional characteristics including age and number of published papers, schooling background effect research. (21) On questioning regarding anxiety, results showed that males experienced lower levels of anxiety compared to females, the results of our study were different from the previous studies (22) According to our study graduating students whether male or female from the Rawal Institute of Health Sciences had same attitude towards research without any significant difference in the responses.

The variation among responses by different years of MBBS regarding the conducting can be explained by the fact of exposure of research to the individuals, and moreover inclusion of research and methodology subject in educational curriculum of community medicine.

We have found great disparity regarding the participation in and attitudes towards research by Rawal institute of medical and sciences students, as well as significant barriers impeding these activities during their education.

There are numerous barriers to research participation during the education. Time was seen to be a significant barrier to pursuing research during medical school as only $14 \%$ of all respondents felt there was adequate allotted time for research endeavors. This barrier is reported by other researchers as well $(12,25)$. Furthermore, only $11 \%$ of respondents felt that there 
were lack of training courses in research methodology in medical school and $50 \%$ agreed that there was no motivation. Another perceived barrier to participation in research was no incorporation in curriculum $25 \%$ agreed to this, which is also highlighted by other studies. $(4,26)$

One of the limitations of our study was the sample recruited for the study is from single institution, so results cannot be generalized to the whole population. Further research is needed with larger sample size and stronger analysis.

The results are concluding that attitude towards research among medical students is variable and individuals who had previous exposure gave more favorable responses towards research compared to those who never had conducted any research. This study shows the need of research oriented programs to improve the awareness and knowledge regarding the research. Proper awareness towards research to students should be indoctrinated at undergraduate level through inclusion of research in curriculum for more favorable attitude which helps in better professional outcomes.

The rationale for facilitating research experience during a medical school education includes the development of an appreciation for research methodology, and subsequent critical appraisal of the medical literature, as well as to foster the interest in medical or basic science research as an academic career.(23) There are numerous conflicting priorities in any medical school curriculum and the role of any mandatory research project or critical inquiry must be balanced against other demands of knowledge and skill acquisition.(24).

\section{Conclusion}

The most important finding in this research was suggestion of enforcement of research project in the curriculum and as a part of their assessment. Keeping some reserved research time and research methodology workshops, courses if made available for students and their mentors, with provision of statistical assistance, will help students conduct research. It is encouraging to note that in this study a large majority of students considered research helpful for their profession and had positive attitudes towards research. However, at the same time, the preponderance of participating students considered it difficult to conduct research, with the most common barriers being lack of time, research training, schooling background, and lack of motivation.

\section{References}

1. Faustino e.oguan jr et al., Attitude and anxiety towards research, its influence, on the students achievement in the course. Asian journal of management sciences \&education vol.3(4) October 2014.

2. Lavis JN, Oxman AD, Moynihan R, Paulsen EJ: Evidence-informed health policy 1-Synthesis of findings from a multi-method study of organizations that support the use of research evidence. Implement Sci. 2008, 3: 53-
10.1186/1748-5908-3-53.

3. Sadana R, D'Souza C, Hyder AA, Chowdhury AM: Importance of health research in South A sia. BMJ. 2004, $328: 826-30$. 10.1136/bmj.328.7443.826.

4. Hennink M, Stephenson R: Using research to inform health policy: barriers and strategies in developing countries. J Health Commun. 2005, 10: 163-80. 10.1080/10810730590915128.

5. Rehan N: Medical research in Pakistan. J Coll Physicians Surg Pak. 2003, 13: 617.

6. Bakken LL, Sheridan J, Carnes M: Gender differences among physician-scientists in selfassessed abilities to perform clinical research. A c ad Med. 2003,78: 1281-86. 10.1097/00001888-200312000-00018.

7. Lloyd T, Phillips BR, Aber RC: Factors that influence doctors' participation in clinical research. Med Edu. 2004, 38: 848-51. 10.1111/j.1365-2929.2004.01895.x.

8. Rosemann T, Szecsenyi J: General practitioners' attitudes towards research in primary care: qualitative results of a cross sectional study. BMC: Family Pract. 2004, 5: 31 10.1186/1471-2296-5-31.

9. Jowett SM, Macleod J, Wilson S, Hobbs FD: Research in primary care: extent of involvement and perceived determinants among practitioners form one English region. $\mathrm{Br} \mathrm{J}$ Gen Prac. 2000, 50: 387-89.

10. Shewan LG, Glatz JA, Bennett C, Coats AJ: Contemporary (post-wills) survey of the views of Australian medical researchers: importance of funding, infrastructure and motivators for a research career. Med J Aust. 2005, 183: 606-11.

11. Askew DA, Clavarino AN, Glasziou PP, Del Mar CB: General practice research: attitudes and involvement of Queensland general practitioners. Med J Aust. 2002, 177: 74-7.

12. Gill S, Levin A, Djurdjev O, Yoshida E: Obstacles to residents' conducting research and predictors of publication. Acad Med. 2001, 76: 47710.1097/00001888-200105000-00021.

13. Levine RB, Herbert RS, Wright SM: Resident research and scholarly activity in internal medicine residency training programs. J Gen Intern Med. 2005, 20: 155-9. 10.1111/j.15251497.2005.40270.x.

14. Bland CJ, Ruffin MT: Characteristics of a productive research involvement: literature review. Acad Med. 1992, 67: 385-97. 10.1097/00001888-199206000-00010.

15. Brocato JJ, Mavis B: The research productivity of faculty in family medicine departments at U.S. medical schools: a national study. Acad Med. 2005, 80: 244-52. 10.1097/00001888200503000-00008.

16. Dr.naser zamani-miandashti et al., The 
relationship between research self-efficacy, research anxiety and attitude towards research: a study of agriculture graduate students., Journal of educational and instructional studies in the world November 2013, volume: 3 issue; 4 article: 09 issn:2146-7463.

17. Sadia shaukat et al Postgraduate students attitudes towards research bulletin of education and research june 2014, vol.36,no.1pp.111-122

18. Papanastasiou,e.c.(2005).Factor structure of the attitudes towards research scale. Statistics education research journal.4(1), 16-26. www.stat.auckland ac.nz/serj

19. Adams,n.a.,\&Holcomb,w.r(1986), Analysis of the relationship between anxiety about mathematics and performance, psychological reports, 59, 943-948

20. Farooq S: Needed a research agenda. J Ayub Med Coll Abbottabad. 2003, 15: 1-2.

21. Khan H, Khawaja MR, Waheed A, Rauf MA, Fatmi Z: Knowledge and attitudes about health research amongst a group of Pakistani medical students. BMC: Med Edu. 2006, 6: 5410.1186/1472-6920-6-54

22. Faustino e.oguan jr et al. ,Attitude and anxiety towards research, its influence,on the students achievement in the course. Asian journal of management sciences \&education vol.3(4) October 2014.

23. Dakik HA, Kaidbey H, Sabra R: Research productivity of the medical faculty at the American University of Beirut. Postgrad Med J. 2006, 82: 462-4. 10.1136/pgmj.2005.042713.

24. Chaturvedi S, Aggarwal OP: Training interns in population-based research: Learners' feedback from 13 consecutive batches from a medical school in India. Med Educ. 2001, 35: 585-89. 10.1046/j.1365-2923.2001.00917.x.

25. Aslam F, Shakir M, Qayyum MA: Why the medical students are crucial to the future of research in South Asia. PLoS Med. 2005, 2: e322-10.1371/journal.pmed.0020322.

26. Aslam F, Qayyum MA, Muhmud H, Qasim R, Haque IU: Attitude and practices of postgraduate medical trainees towards research - a snapshot from Faisalabad. J Pak Med Assoc. 2004, 54: 534-6. 